\title{
A lógica do fantasma na passagem da modernidade à contemporaneidade
}

\section{The logic of the phantasm in the passage from modernity to contemporaneity}

\section{La lógica del fantasma en el paso de la modernidad a la contemporaneidad}

\section{Flavia Lana Garcia de Oliveira*}

Universidade Federal do Rio de Janeiro - UFRJ, Rio de Janeiro, Rio de Janeiro, Brasil

\section{Tania Coelho dos Santos**}

Universidade Federal do Rio de Janeiro - UFRJ, Rio de Janeiro, Rio de Janeiro, Brasil

\begin{abstract}
RESUMO
A clínica contemporânea nos confronta com sujeitos sujeitados a imposições maciças do gozo. As fixações pulsionais comparecem, muitas vezes, livres do ocultamento fantasmático no inconsciente. Prevalece um tipo de laço com o Outro que remonta às modalidades mais arcaicas de relação do eu com o objeto. Diante deste cenário, interrogamos qual seria o estatuto do fantasma hoje. Nosso fio condutor será a hipótese de um rebaixamento da eficácia simbólica da autoridade paterna em conter o egoísmo pulsional que se manifesta na radicalização dos apelos ao gozo ilimitado. A gramática fantasmática é um anteparo simbólico-imaginário que permite interpretar a posição libidinal de cada um diante do real do desejo do Outro. 0 desmentido da função do pai como agente da castração, engendra um sujeito voraz, cuja debilidade do eu resulta em alterações psicóticas do caráter.
\end{abstract}

Palavras-chave: fantasma, clínica contemporânea, corpo, pulsão.

\begin{abstract}
The contemporary clinic confronts us with subjects subject to massive impositions of jouissance. Drive fixations often appear free from the phantasmatic occultation in the unconscious. A kind of bond prevails with the Other that goes back to the more archaic forms of relation of the self to the object. Faced with this scenario, we ask what the status of the phantasm would be today. Our guiding principle will be the hypothesis of a debasement of the symbolic efficacy of paternal authority in containing drive's egoism, which manifests itself in the radicalization of the calls to unlimited jouissance. The phantasmatic grammar is a symbolic-imaginary screen that allows for interpreting the libidinal position of each one when faced the real of the desire of the Other. The disavowal of the paternal function as an agent of castration produces a voracious subject, whose weakness of self results in psychotic alterations of character.
\end{abstract}

Keywords: phantasm, contemporary clinic, body, drive. 


\begin{abstract}
RESUMEN
La clínica contemporánea nos confronta con sujetos sometidos a imposiciones masivas del goce. Las fijaciones pulsionales, frecuentemente, están libres del ocultamiento fantasmático en el inconsciente. Prevalece un tipo de lazo con el Otro que se remonta a las modalidades más arcaicas de relación del yo con el objeto. Ante este escenario, interrogamos cuál sería el estatuto del fantasma hoy. Nuestro hilo conductor será la hipótesis de un descenso de la eficacia simbólica de la autoridad paterna en contener el egoísmo pulsional que se manifiesta en la radicalización de las llamadas al goce ilimitado. La gramática fantasmática es una mampara simbólicaimaginaria que permite interpretar la posición libidinal de cada uno ante el real del deseo del Otro. El desmentido de la función del padre como agente de la castración, engendra un sujeto voraz, cuya debilidad del yo resulta en alteraciones psicóticas del carácter.
\end{abstract}

Palabras clave: fantasma, clínica contemporánea, cuerpo, pulsión.

\title{
1 A lógica do fantasma é a lógica da inserção do sujeito em um discurso
}

De acordo com Chemana (2013), raros são os estudos em psicanálise que se dedicam à lógica do fantasma em uma perspectiva diacrônica. Somente assim se poderia levar às últimas consequências as mudanças em sua apresentação clínica ao longo das sucessivas mutações discursivas que permearam o laço social nas últimas décadas. Consideramos que esse exercício é indispensável a uma clínica do sujeito que leve em conta uma clínica da civilização. Sabemos que a vacilação da eficácia simbólica da autoridade paterna na distribuição dos gozos, o avanço desgovernado do egoísmo pulsional e da absolutização do apelo ao gozo irrestrito são alguns dos aspectos mais evidentes da torção ocorrida na transição da modernidade à contemporaneidade (Coelho dos Santos, 2015). Qual seria o estatuto do fantasma nos dias atuais? A função paterna ainda organiza a dinâmica pulsional em torno da castração? Prevaleceria ainda a tendência histérica a denunciar o Outro como barrado? Ou o gozo parricida do obsessivo? Ou seria preciso recuar aquém da função paterna e das angústias de castração, onde se alojam as fixações pré-edípicas?

O fantasma histérico de sedução foi o ponto de partida freudiano para a elucidação da constituição psíquica que é própria à modernidade. Ele desvela que as histéricas padeciam de reminiscências do traumatismo do encontro com o sexual. Sob o enredo imaginário dos relatos de sedução sexual por parte do pai, triunfa a lógica da organização edipiana e da inscrição da castração. Deste modo, as narrativas histéricas tratavam o encontro traumático com o desejo do Outro. Desde os primórdios da psicanálise, a função paterna, enquanto um elemento exterior à relação mãe e filho, introduz no psiquismo uma marca traumática, perante a qual o sujeito 
experimenta forçosamente uma relação de submissão. A outra face desta relação com o pai é a dívida simbólica que o sujeito contrai com aquele que liberta a criança de sua indiferenciação com o Outro materno. Eis porque o fantasma edipiano revela também um forte laço de amor ao pai na base das relações de parentesco que regulam e mantém o pacto social.

A abordagem freudiana da construção da fantasia permite situar a função central da castração na constituição do sujeito. Ergue-se como uma resposta defensiva frente à impossibilidade de tudo satisfazer, ou à impossibilidade de tudo significar. A formalização da lógica do fantasma (fantasme) por Jacques Lacan articula em uma fórmula o sujeito barrado ao objeto perdido. Permite distinguí-lado devaneio como formação imaginária (phantasie), risco que se corre com a manutenção da terminologia fantasia. Para Lacan, essa engrenagem logicizada é organizadora da constituição subjetiva. De um lado, é fundada através do laço com o Outro da linguagem, de outro, é articulada a um resto de corpo, que serve de suplemento (mais-degozar) ao objeto perdido. Ao inserir o sujeito em um discurso, que é também uma modalidade de laço com o Outro simbólico, o sujeito é extraído da relação de objeto passivo do Outro materno. A robustez desse laço depende de uma transmissão competente em articular a pulsão a um discurso que funcione como metáfora e veicule a potência civilizatória da sublimação. Freud nos forneceu ao longo de sua obra pistas preciosas acerca de como a transmissão parental pode comportar esta característica.

Uma criança é concebida para fazer suplência à não relação sexual dos pais na maior parte dos casos. Lacan (1966-1967/2004, p. 16, tradução nossa) sublinha que "é do imaginário da mãe que vai depender a estrutura subjetiva da criança". Na melhor das hipóteses, no imaginário materno, a criança pode vir a ser alguma coisa que preencha a falta constitutiva da realidade humana. Partindo de seu próprio fantasma de completude, a figura materna acolherá e subjetivará a criança real. Por este motivo, a magnitude do desejo da mãe é a fonte da força fálica com a qual o filho será revestido. Quando a dimensão estrutural da falta se evidencia para a criança, ela é confrontada simultaneamente a um vazio em si própria e no Outro. Será preciso, então, dar um destino a essa dupla hiância. Como afirma Lacan (1966-1967/2004), a essa falta, que é de estrutura, é necessário conferir uma função lógica. A criança passará então pela experiência de precisar se situar em relação à falta do Outro materno. Para advir como sujeito, enfrentará a necessidade de simbolizar a dimensão real do desamparo (Hilflosigkeit). Esse é um momento nodal na constituição subjetiva. Será preciso simbolizar uma parte de si mesmo como definitivamente perdida. Aquela parte que acreditou um dia ser tudo para o Outro materno. A condição para a instauração desse tempo é que o objeto seja separável do Outro. 
Isso só é possível se o Outro materno pode admitir que a criança não é tudo para ela.

O fantasma é o mecanismo de captura do corpo pulsional (objeto perdido) no laço com o Outro portador de uma falta. Em seu segundo ensino, Lacan (1964/1998c) formalizou o papel do Outro na constituição psíquica por meio das operações de alienação e de separação. O processo de alienação descreve o momento em que 0 futuro sujeito, até então inexistente e indiferenciado com o real, se aliena aos significantes do Outro. Alienar-se é um movimento de abertura e direcionamento ao Outro, pelo qual se ingressa na cadeia significante da linguagem reguladora das relações humanas. Desse modo, uma miríade de palavras, regras, ordens e textos de grande amplitude passam a funcionar automaticamente e de maneira présubjetiva. São exteriores ao sujeito e pré-determinam as ligações de parentesco, permissões e proibições (Brodsky, 2014). O sujeito não possui ingerência sobre essa ordem simbólica, pois ela the é transmitida pelo Outro. Portanto, a alienação é o primeiro passo para usufruir desse repertório simbólico, graças ao encontro com uma discursividade que orienta um modo de estar no mundo. Já a separação marca a instituição do sujeito do inconsciente (Lacan, 1964/1998c). O corpo próprio ex-siste à linguagem. Por essa razão, o real do gozo é irredutível à simbolização através do discurso do Outro, e se condensa como objeto a. A extração desse objeto, como objeto perdido, está destinada a funcionar como causa do desejo, se, e somente se, os pais como seres sexuados alcançam transmitir 0 real em jogo na castração. A função paterna será o vetor que desloca a criança da posição de objeto da mãe, se esta puder ocupar a posição de objeto a e for causa de seu desejo enquanto homem. Só então ela poderá ser não-toda mãe.

A estruturação da lógica do fantasma se alicerça nessa trajetória que vai da abertura à alienação até a separação. Há um lembrete de máxima importância: a operação de separação não culmina em um afastamento do Outro. Trata-se, sobretudo, do distanciamento do objeto de gozo, que pode enlouquecer um sujeito caso este se mantenha identificado com ele. A separação ejeta o sujeito dessa posição de objeto maciço do Outro. O objeto é recalcado e não mostra mais seu verdadeiro rosto. Em torno dele, é construído um circuito, onde a pulsão contorna sua ausência para alcançar o Outro (Lacan, 1964/1998c). O Outro, portanto, não desaparece por completo. Ao contrário, uma nova versão do Outro é instituída. O Outro barrado porta a marca real de uma falta que o torna desejante. A busca por um complemento de gozo no Outro, também será redimensionada com uma nova roupagem. A falta-a-ser do sujeito será velada por meio de uma versão fantasmática acerca de seu lugar no desejo do Outro. O sujeito agora é o intérprete de sua própria história. Ele passa a usufruir, inconscientemente, da condição de 
objeto a do Outro, valendo-se de uma ficção própria (fantasma) acerca do seu valor para ele.

Desse modo, o fantasma torna o real suportável para o sujeito. Lacan (1957-1958/1999) o examina como uma defesa que escamoteia a perturbadora falta do Outro. As exigências pulsionais agora incidirão no psiquismo organizadas por um enredo. O fantasma desempenha a função simbólica de enquadrar, emoldurar a realidade. Portanto, ao mesmo tempo é uma espécie de guia face aos eventos que requerem respostas do aparelho psíquico, e um instrumento de mediação para o acesso às satisfações pulsionais (Nascimento, 2010). Sua estrutura lógica pressupõe a primazia da função paterna na regulação da ordem simbólica, na organização do lugar do Outro e de sua ação sobre a força pulsional.

\section{2 o paradigma do fantasma na modernidade: Bate-se em uma criança}

Freud (1917/1996c) correlacionou a emergência do fantasma a uma mudança no estatuto do objeto. Diferentemente do caminho da formação dos sintomas, que se trilha por condensações e deslocamentos de representações, o fantasma se estabelece por meio de uma fixação pulsional a um objeto parcial. A condição para que haja fixação é uma perda inicial. O fantasma preserva um resto depois do recalque das satisfações primárias autoeróticas e dos desejos infantis.

Na sequência de sua obra, Freud (1919/1996d),em seu artigo intitulado Bate-se em uma criança, nos apresenta a tese de que o fantasma é "fundamental", isto é, trata-se do aspecto mais central do funcionamento psíquico. Esclareceu que, em sua estruturação, haveria um desdobramento em três tempos articulados ao percurso edípico. Sua primeira versão costuma ser rememorada através da frase "Meu pai está batendo na criança que eu odeio" (Freud, 1919/1996d, p. 201). O pai surge, neste nível, como uma figura imaginária que castiga um rival hostilizado pela criança, geralmente um irmão ou uma irmã. A presença deste semelhante acarreta a ameaça de desprestígio na disputa amorosa junto aos pais. Freud ressalta a instauração de uma posição fortemente tomada pelos afetos de ódio e desprezo por tudo o que representa para a criança a iminência de ser destronada da posição de objeto exclusivo do amor parental. Através do fantasma, ela tenta reforçar seus interesses egoístas, restituindo a crença em sua onipotência, reafirmando que: "O meu pai não ama essa criança, ama apenas a mim" (Freud, 1919/1996d, p. 202).

A segunda apresentação do fantasma - Sou batido por meu pai- traz uma reversão decisiva para a constituição psíquica. Freud 
(1919/1996d) avalia esse tempo como necessário e específico. Ele não emerge na experiência analítica como uma recordação até então recalcada, nem como um enigma decifrável pela interpretação, mas como uma construção que implica o trabalho do analista. O fantasma ganha sustentação em uma posição masoquista, denominada por Freud como uma atitude feminina frente à castração. Tal enredo introduz o recalque da escolha objetal incestuosa, com a inscrição de que a plenitude do amor incestuoso está fadada à desilusão. Trata-se de um tempo de angústia aguda, pois é acompanhado pelo surgimento de um sentimento inconsciente de culpa. Nas palavras de Freud (1919/1996d, p. 205), "esse ser espancado é agora uma convergência do sentimento de culpa e do amor sexual. Não é apenas o castigo pela relação genital proibida, mas também o substituto regressivo daquela relação".

O componente masoquista invoca a delicada regulação exercida pela instância do supereu à posição de objeto. A incidência do sentimento inconsciente de culpa e da necessidade de punição como reguladores da pulsão resultam desse tempo. O supereu se anuncia como um recurso civilizatório capaz de aparelhar o eu para frear as tendências pulsionais do isso. O sacrifício e a renúncia pulsional são o "preço a pagar" para entrar no regime paterno. Porém, as tendências masoquistas despertadas neste passo da produção fantasmática evidenciam que, a nível inconsciente, a luta para não permanecer na posição de objeto leva à representação psíquica do espancamento como um esforço paradoxal de contenção.

Em sua etapa final, o enredo edípico é reduzido logicamente a um enunciado mais abstrato: Bate-se em uma criança. Freud designa essa redução a uma fórmula impessoal como uma guinada pulsional, em direção à posição ativa no exercício da escopofilia. Nesse registro, as fixações primárias habitam o indivíduo residualmente, como uma espécie de "cicatriz narcísica" do complexo de Édipo (Freud, 1919/1996d, p. 208).

$\mathrm{Na}$ orientação lacaniana, Bate-se em uma criança pode ser considerado o paradigma psicanalítico do fantasma como resíduo das relações primitivas do sujeito com o Outro da linguagem. Lacan (1957-1958/1999) extraiu dos três tempos enumerados por Freud os efeitos de simbolização da incidência do significante sobre o corpo. 0 destinos para o gozo pulsional balizados pela metáfora paterna e pela significação fálica inscrevem-se através desse processo. Tomando o segundo tempo do fantasma como o da instalação efetiva do complexo edípico, Lacan acrescenta à cena a presença de um chicote, valorizando sua dimensão simbólica. A ação de bater é equiparada por ele a uma metáfora da incidência do significante Nome-do-Pai. Ser batido é se tornar sujeito barrado, ou seja, é ser inscrito na lógica fálica da castração através da operatividade do Outro paterno na transmissão do desejo. Lacan reitera que "[...] a única coisa que 
persiste é o material do significante, esse objeto, o chicote, que permanece como um signo até o fim, a ponto de se tornar o pivô e, diria eu, quase o modelo da relação do sujeito com o Outro" (Lacan, 1957-1958/1999, p. 251-252).

É interessante sublinhar que, ao abordar esta questão, Lacan toca com exatidão nas ambiguidades que caracterizam a relação do sujeito masoquista com o Outro paterno: "Há sempre, na fantasia masoquista, uma faceta degradante e profanadora, que indica ao mesmo tempo a dimensão do reconhecimento e o modo de relação proibido do sujeito com o sujeito paterno. É isso que constitui o fundo da parte desconhecida da fantasia" (Lacan, 1957-1958/1999, p. 255). A capacidade de atravessar a angústia do encontro com o desejo do Outro, isto é, referente à falta de um objeto que proporcione um gozo sem inconvenientes, é um ingrediente imprescindível para a superação da rebeldia masoquista. A responsabilização pelos direitos e pelos deveres no pacto civilizatório só é possível por meio da subjetivação da marca do interdito paterno. Apenas assim, a ferida narcísica pode "cicatrizar-se" e não deixar transbordar a hemorragia libidinal que caracteriza a melancolia e outros quadros em que a posição masoquista de objeto se faz ver de modo radical e vertiginoso.

O matema lacaniano do fantasma ( $\$ \diamond$ a) designa a articulação entre o sujeito barrado - efeito da inconsistência do Outro, onde um significante $\left(S_{1}\right)$ assume o valor de representante do sujeito para outro significante $\left(S_{2}\right)$ - e o objeto a, uma parte do corpo erógeno que suplementa imaginariamente a perda de gozo imposta pelo simbólico. Em suma, a lógica do fantasma pretende apreender 0 tempo mítico de anuência do sujeito, ou não, à entrada do Outro paterno como interditor do gozo incestuoso e promotor do gozo sexual. Todo fantasma neurótico é "uma aspiração à completude imaginária e à saciedade pulsional" (Coelho dos Santos, 2016a, p. 5), caracterizando-se por um "a mais" de gozo que vem no lugar de um "a menos" e tenta fabricar a plenitude amorosa. Longe de ser uma formação exclusivamente simbólica, análoga à infinitude criativa das produções do inconsciente recalcado, a escrita fantasmática circunscreve o real impossível. Irrompe como algo não tocado, não atingido, nem atingível diretamente pelo significante (Miller, 2002).

\section{A problemática do fantasma na contemporaneidade: debilidade, psicotização e alterações no caráter}

É preciso avaliar o impacto nos arranjos fantasmáticos do enfraquecimento da função subjetivadora da metáfora paterna e do seu significante privilegiado, o falo. A emergência do fantasma no processo de subjetivação do homem moderno assegura a antinomia 
entre o significante e a Coisa. Este é o princípio que, mais além do princípio do prazer, permite moderar os processos primários por meio da hegemonia dos processos secundários. O sacrifício do gozo autoerótico é uma dívida simbólica cobrada em nome do pacto entre direitos e deveres que consolida o tecido social. Presume-se que o objeto a seja extraído, e só possa apresentar-se esvaziado pela subtração de gozo. Sua positivação como suplemento do gozo perdido, mais-de-gozar, é uma fixação libidinal, mas não é o gozo puro, pois traz a marca da castração. De acordo com Lacan (19621963/2005), trata-se de um objeto postiço. Por isso, a identificação ao falo imaginário não é completa, é marcada pela castração. Não absorve o eu, nem dilacera de uma vez por todas a relação com a realidade.

A clínica contemporânea nos confronta, entretanto, com sintomas que aspiram à positivação do objeto de gozo. As fixações no objeto parcial encontram-se desmascaradas sem o invólucro do velamento no fantasma inconsciente. Essa exposição do gozo sem o véu do recalque (Coelho dos Santos, 2016b), desnuda a prevalência de um laço que remonta às modalidades mais arcaicas de relação do eu com o objeto. Freud (1905/1996a) definiu a fase oral da organização prégenital da libido como um estágio de caráter canibalesco. A relação ao objeto visa a incorporação deste ao eu, por meio de um ato de devoração. No laço oral com o Outro, não existe o reconhecimento do objeto como não pertencente ao eu. A experiência da perda de objeto, por sua vez, se expressa como um vazio insuportável que arrasta o sujeito na direção de uma busca voraz por compensações narcísicas. Nesse regime da economia pulsional, o fantasma não resultada ação do supereu sobre o eu, marcando-o com o selo da dívida simbólica com o Outro. Na discursividade contemporânea, a perda do objeto que universaliza os homens e que deveria ser o bilhete de entrada no pacto simbólico, é vivida como um estigma individual. Incapaz de subjetivar a castração por meio da dívida simbólica, o sujeito contemporâneo acredita que foi prejudicado, reivindica ser tratado como exceção e reclama do pai, da sociedade e da justiça o direito à reparação. A aparente psicotização do laço com a realidade, a debilidade do eu e as alterações no caráter configuram três linhas de abordagem interconectadas entre si que lançam luz sobre a apresentação do fantasma nas neuroses contemporâneas. Elas nos desafiam tanto no sentido de compreender qual é sua relação com a castração, como no sentido de encontrar novos instrumentos para interpretá-las e tratá-las. É o que faremos em seguida. 


\subsection{A psicotização do laço com a realidade: um efeito do desmentido banal da autoridade simbólica}

A discussão acerca do estatuto do fantasma na psicose pode ser um caminho para estabelecer um novo entendimento sobre o crescimento da atitude de recusa à castração na sociedade contemporânea. Lembramos que Lacan (1958/1998a) aludiu à dimensão fantasmática na estrutura psicótica para descrever o pensamento que domina Schreber: "como seria belo ser uma mulher na hora da copulação". Seu viés psicótico se pronunciou quando tal ideia se converteu na certeza de que era a mulher de Deus. Para Schreber, o fantasma de feminização seguramente proporcionou alguma consistência ao seu eu, mas camuflou muito pouco a malignidade do Outro gozador. Por essa razão, como observam Maleval et al. (2009), ele se revolta contra a ideia de ser uma mulher sofrendo a cópula. Os autores ressaltam também que a falha da construção fantasmática no psicótico evidencia-se na miscelânea de cenários imaginários desprovidos, tanto da capacidade de enquadrar a realidade, quanto de manter o gozo à distância. Como a estrutura psicótica fracassa em extrair o objeto a, também não alcança a simbolização da falta. A ausência do falo como significante da diferença sexual conduz o sujeito psicótico à certeza inabalável de uma identidade sexual. Para o neurótico, seu ser sexual não é uma identidade, é uma identificação a um ideal do seu sexo que está sempre em vias de se realizar, é duvidosa e não se atinge nunca. Para o psicótico, diferentemente, o Outro não tem esse caráter de tesouro do significante. Por essa razão, seu ser pode ser tomado por uma significação ilimitada, não barrada. Por essa razão, Miller (2006) afirma que o sintoma psicótico é o fantasma do Outro, não cumprindo a função de aplacar o gozo. Pelo contrário, deixa o sujeito aprisionado à posição de objeto de um Outro gozador. Maleval et al (2009) recordam que, sem a divisão subjetiva, o registro imaginário "coloniza" todo o terreno da significação, entregando o sujeito a um modo de gozo imutável. Por conseguinte, o eu se torna um véu muito frágil e não recobre o vazio do sujeito.

Podemos observar alguns componentes psicóticos nas estruturas neuróticas na contemporaneidade: a falência da função fálica na apreensão do desejo do Outro e na negativização do gozo; a hiperconsistência do Outro; as satisfações pulsionais a céu aberto e falhas importantes no enquadramento da realidade que repercutem na relação do sujeito ao seu corpo. Como explicar a presença de tais elementos tipicamente psicóticos? Seriam sujeitos borderline? Seriam casos de psicose ordinária, isto é, de psicoses não desencadeadas, medicadas ou estabilizadas por meio de psicoterapias?

Em lugar de tomar o caminho da estrutura psicótica para abordar esses casos, vamos retomar a hipótese freudiana acerca das 
neuroses contemporâneas (Freud, 1933/1996f). Para não cair numa simples questão terminológica, advertimos o leitor de que adotamos a hipótese de Coelho dos Santos (2015) de que vivemos uma época em que predominam discursividades desconstrucionistas pósmodernas que se caracterizam pelo desmentido do Nome-do-Pai e do valor simbólico do significante falo. Não enfrentamos uma pura e simples foraclusão psicótica do Nome-do-Pai ou do significante que o representa no campo do Outro. Há todo um discurso e um laço social que sustenta a desconstrução das referências simbólicas. Encontramos na clínica, sobretudo, indivíduos que professam uma posição do tipo "eu sei, mas... mesmo assim". O resultado é a fragilidade da remediação fálica, a densificação da posição de objeto diante deum grande Outro hiperconsistente. Essa aparente psicotização da relação à realidade é a consequência da instalação do desmentido banal da autoridade paterna no laço social contemporâneo. De acordo com Coelho dos Santos (2015, p. 5), "a hipermodernidade [...] consiste no desmentido da função do semblante do Nome-do-Pai de agente da castração, de supereu".

Segue-se, em conformidade com essas hipóteses, que a perturbação da referência ao Outro da Lei simbólica repercute na posição subjetiva dominante. Esta última se caracteriza por uma referência ao Outro marcada pela obstinada depreciação, pela destituição e pelo rebaixamento. Desponta, assim, um funcionamento subjetivo que, apesar de ser neurótico, distingue-se por desmentir continuamente que o gozo ilimitado seja impossível, que a sucessão geracional e que a diferença geracional comportem alguma coisa de irredutivelmente real. Como avançou Coelho dos Santos (2016b), no rastro dos discursos pós-modernos, desconstrucionistas, todos os semblantes foram reduzidos a meras representações. Acredita-se que a história da humanidade demonstraria amplamente que tudo que o homem inventou está destinado a desfazer-se e ser substituído por novas representações. Nada é real! Tudo que é sólido desmancha no ar. Desvencilhado do lastro do real, o eu destes indivíduos torna-se irremediavelmente débil.

\subsection{A debilidade do eu}

Segundo Freud (1926/1996e, 1940/1996g), a debilidade do eu é inerente aos primórdios da constituição do psiquismo, pois o eu se enraíza no caos pulsional do isso. Emergirá por meio de uma "nova ação psíquica" que consiste em unificar as pulsões autoeróticas em direção a um novo objeto de amor, a imagem totalizada de si mesmo. Somente depois da constituição dessa primeira identificação, haverá distinção entre o eu e o não-eu e será possível erguer alguma barreira em relação ao excesso pulsional. Porém, esse primeiro aparelhamento identificatório é narcísico e frágil. Somente uma 
organização edificada graças à identificação secundária ao ideal do eu-e sua ligação ao supereu paterno pós-edipiano - poderá reunir a potência necessária para cumprir essa tarefa a contento. Munido dessas fontes de regulação, o eu institui o recalque de certas tendências libidinais (Freud, 1926/1996e). Diante da divergência entre realidade e pulsão, o eu toma partido do mundo externo e se envolve em um conflito psíquico contra o excesso pulsional (Freud, $1926 / 1996 e)$. Através da emissão da angústia como um sinal de perigo, ele também se torna hábil na antecipação de uma satisfação pulsional questionável e deflagradora de desprazer caso seja realizada. As neuroses derivam da inibição da função de síntese do eu diante da insistência das pulsões recalcadas. Freud especifica que 0 elemento patogênico não reside nas discordâncias inevitáveis entre a realidade e o isso, mas, acima de tudo, na mediação inapropriada deste embate pelo eu. $\mathrm{O}$ eu é moldado pela realidade e se opõe ao isso, porém fracassa no exercício de sua influência. Acaba por renunciar a algumas de suas atividades para evitar um novo choque, o que lhe gera grande dispêndio de força psíquica. Por um lado, o eu se desgasta no esforço vão de defesa contra os sintomas, mantendose débil em suas atividades; por outro lado, as pulsões perseguem insistentemente seus objetivos, a despeito dos interesses daquele.

A sofisticação do aparelho psíquico - com o estabelecimento de um eu suficientemente instrumentalizado para avaliar as restrições da realidade e responder com êxito aos impulsos do isso - depende de sua aliança com o supereu paterno. A formação dessa versão do supereu deriva de uma transformação pulsional (Freud, 1933/2010). Freud salienta que o supereu não é construído segundo o modelo dos pais, mas do supereu dos pais. Preenche-se com o mesmo conteúdo deste, torna-se "veículo da tradição, de todos os constantes valores que assim se propagaram de geração a geração" (Freud, 1933/2010, p. 205). Assim, a estruturação do eu é oriunda da transmissão geracional da Lei simbólica encarnada e particularizada em cada figura do Outro parental.

Na contemporaneidade, a função parental de interdição do gozo e de transmissão da diferença sexual é debilitada pelos discursos desconstrucionistas. As neuroses comparecem agravadas pela debilidade do eu no manejo do excesso pulsional. Observa-se também uma insubmissão relativamente à ferocidade das exigências pulsionais que são excitadas pelo próprio laço social consumista. A realidade que inclui o real da castração é experimentada como insuportável. $\mathrm{O}$ eu responde debilmente, diluindo-se na indiferenciação com o isso e retraindo-se nas gratificações pulsionais compulsivas. Prevalece, por outro lado, a parceria ambígua com o supereu paterno que oferece suporte psíquico adequado a um laço com o Outro para transmissão efetiva do patrimônio simbólico geracional de cada configuração familiar e cultural. 
Lacan (1964/1998c) abordou tanto o sujeito débil, quanto o psicótico, a partir da holófrase do par primordial de significantes. A holófrase é uma figura gramatical caracterizada pela aglutinação de uma frase em uma única locução. Sob a ótica da estrutura da linguagem, ela diz respeito ao acoplamento de $S_{1}$ e de $S_{2}$ sem espaço intervalar. Tal solidificação gera o engessamento dos efeitos da cadeia significante, emperrando a possibilidade do sujeito entrar no jogo das representações que the permitiria questionar e interpretar a significação do que ele representa para o desejo do Outro (Santiago, 2005). Com esse entrave da remissão significante, o sujeito fica em suspenso e retido como objeto.

Nessa vertente, Lacan (1964/1998c) descreve primeiramente um tipo holofrásico próprio às psicoses, relativo à foraclusão da metáfora paterna. Neste caso, a organização do Outro na ordem simbólica fica totalmente comprometida, dada a impossibilidade da substituição de $\mathrm{S}_{1}$ (significante mestre) por $\mathrm{S}_{2}$ (saber). Não há advento do sujeito, nem causalidade sexual no sentido atribuído a $S_{2}$. Fica-se à mercê da imposição de significantes mestres $\left(S_{1}\right)$ isolados que retornam como algo de real, dessubjetivados e petrificados nos fenômenos alucinatórios e na certeza delirante (Santiago, 2005). Em seguida, Lacan distingue um outro tipo de holófrase, que ele define como a debilidade. Tal holófrasenão produz o desaparecimento absoluto do sujeito, mas uma submissão exacerbada ao Outro que pode se assemelhar, em parte, à posição psicotizada. No entanto, é importante ressaltar que, para Lacan, o mecanismo psíquico explicativo da debilidade não reside na foraclusão do Nome-do-Pai. É preponderante, nestes casos, a inibição radical associada à intensa denegação da castração. São sujeitos aderidos a identificações imaginárias, imersos na incapacidade de elaborar um saber inconsciente relativamente à Lei simbólica. Em lugar de um sujeito que se interroga sobre a causa do desejo - marcado pela necessária interpretação da falta do Outro -encontramos um sujeito desorientado, perdido no enxame de significantes, incapaz de extrair um S1, isto é, o significante que designaria uma exceção capaz de fundar o conjunto de significantes. Quanto a este ponto, Coelho dos Santos (2016b) afirma que, desmentido deste significante em posição de exceção, vai levá-lo secundariamente a buscar a identificação ao grupo de pares por meio de um elemento imaginário. São os grupos monossintomáticos e as tribos que se organizam em torno das políticas identitárias pós-modernas.

\subsection{Alterações no caráter}

Nas neuroses contemporâneas, se observa a predominância de um modo de alienação ao Outro hiperconsistente. Evidencia-se que a ordenação simbólica da realidade é precária. O sintoma não é uma 
formação de compromisso, pois o parceiro da pulsão não é o supereu pós-edípico. Revela-se a serviço de um Outro "parceiro-aditivo" incentivador das satisfações imediatas e desmedidas. A formação do caráter não será baseada na aliança sublimatória da pulsão com o pacto civilizado. O supereu pós-edípico é o vetor das sublimações necessárias à edificação de um caráter que seja capaz de enfrentar as exigências da pulsão e as limitações da realidade. Sem o recalque das pulsões e de suas modificações sublimatórias, o eu é parasitado por fortes injunções de gozo.

Freud (1916/1996b) se debruçou sobre os tipos de caráter encontrados no trabalho analítico, concebendo-os como atitudes diante da falta de satisfação. Ele menciona alguns indivíduos que reivindicam serem tratados como "exceção", convencidos de que já renunciaram e sofreram bastante e de que, por este motivo, possuem o direito de serem poupados de novas exigências e impossibilidades impostas pela vida. Otto Fenichel, na década de 1950, acrescentou coordenadas importantes a esta linha de investigação. Observa que o agravamento das psicopatologias do caráter se deveu à frouxidão das intervenções educativas na época. O interesse psicanalítico por esse assunto deve-se à nova configuração das neuroses verificada progressivamente, na qual predominam respostas marcadas pela limitação crônica da plasticidade do eu e seu endurecimento identificatório à posição de objeto (Coelho dos Santos \& Oliveira, 2017).

Fenichel (1957/1973) ressalta que a psicanálise partiu da investigação dos sintomas neuróticos enquanto fenômenos estranhos ao eu e que não condiziam com o "caráter", isto é, com o modo habitual de conduta que delimita a personalidade. No entanto, com as alterações nos alicerces da constituição do eu ao longo das mutações discursivas do laço social, a fronteira entre sintoma e caráter fica mais turva. Em muitas neuroses dos dias de hoje, já não se trata de uma personalidade uniforme que, em certo momento, é perturbada pela aparição de atos e impulsos mortíferos, mas sim de uma personalidade flagrantemente tomada pelo excesso pulsional. A fragilidade da simbolização inconsciente repercute na rigidez do eu contra a angústia. A austeridade da conduta tolhe maciçamente a vivacidade e a elasticidade do eu. Ao invés de um constante conflito entre impulso e defesa, encontramos resíduos congelados de conflitos anteriores. As neuroses clássicas claramente delineadas cedem lugar a transtornos menos definidos, que são mais inconvenientes para aqueles que os cercam do que para seu próprio eu (Fenichel, 1957/1973). Desse modo, as psicopatologias do caráter retratam perturbações narcísicas em que a divisão subjetiva sucumbe e a posição de objeto se cristaliza por meio de modos de gozo maciços, perversamente instalados no eu. 
Portanto, na época atual, a reivindicação de ser tratado como exceção, da qual nos falava Freud, vem se expandindo. A impossibilidade de se ter tudo não se inscreve por meio da diferença sexual, por meio do falo como significante do desejo. Em lugar dessas referências clássicas do processo de subjetivação da falta na cultura, encontramos indivíduos revoltados e aderidos à certeza deque foram privados de alguma coisa que lhes é devida de direito. Acreditam que precisam ser indenizados.

\section{A discursividade contemporânea e a lógica do fantasma}

Existe uma relação entre o progresso da ciência, a era dos direitos e a reivindicação de ser tratado como exceção. Coelho dos Santos (2012, p. 18) enuncia:

À medida que a ciência assegura a transposição de antigos limites, cresce a potência da demanda de usufruir de satisfações inéditas. O campo do direito, desde a Declaração Universal dos Direitos Humanos (ONU, 1948), não cessa de promover o direito ao desejo de cada um, muitas vezes em detrimento do direito de todos. A velha máxima - a liberdade de cada um termina onde começa a do outro - está francamente caduca.

As neuroses clássicas ou modernas caracterizam-se pela hegemonia do mecanismo psíquico do recalque da sexualidade. O fantasma é uma montagem pulsional que contorna o vazio do objeto incestuoso (gozo a menos) para somente reencontrá-lo como um resto que proporciona um gozo a mais. O fantasma é uma articulação entre um gozo esvaziado e um gozo reencontrado como resíduo. Lacan (1960/1998b) adverte que o que o neurótico mais teme é a castração. Há uma falha estrutural tipicamente neurótica na apropriação da genuína função do falo, o que vai levá-lo a abrigar-se na crença de que o Outro é completo e demanda sua castração. Nas neuroses contemporâneas, essa interpretação, própria ao tempo primitivo e infantil do laço com a realidade, é fomentada pela utopia do Estado do Bem-Estar Social e pela lógica da indenização ao consumidor lesado. A era dos direitos fomenta a posição fantasmática masoquista. O Outro contemporâneo é o Estado Providência. Deve assegurar saúde, educação, habitação, trabalho, esporte, lazer e felicidade. A esse respeito, Coelho dos Santos (2017, p. 31-32) argumenta:

O século XIX foi o século das Constituições liberais individualistas e que configuram o clássico Estado de Direito. O 
novo Estado Constitucional dos direitos fundamentais é menos marcado pela preocupação com a liberdade e mais com a justiça que abrangem os direitos sociais. Foram os filósofos políticos do Socialismo Utópico (Owen, Fourier, Saint-Simon e Proudhon) além dos fundadores do Socialismo Científico (Marx e Engels) - críticos do capitalismo - que advogaram a reforma social ou a apropriação coletiva dos meios de produção seguida da extinção do Estado.

Sendo assim, dificilmente compreenderemos a posição do sujeito que reivindica ser tratado como exceção se não levarmos em conta os efeitos da ideologia social democrata e o mito do Estado do Bemestar social. A mesma autora prossegue mostrando que:

A passagem do clássico Estado de Direito ao novo Estado Constitucional de direitos fundamentais inaugura, entretanto, uma época de ruptura dos princípios de legalidade e legitimidade. A ação corrosiva de ideologias organicistas antagônicas ao Estado Liberal, em virtude de conflitos sociais cada vez mais agudos, desestabilizaram o ordenamento liberal conduzindo à suspeição contra a legalidade, agora considerada antagônica da legitimidade. Cresce o sentimento anarquista de que o Estado de direito é legal, mas não é legítimo". (Coelho dos Santos, 2017, p. 32).

A ideia de que o que é legal não é, necessariamente, legítimo corrompe toda aspiração a direitos e deveres universais. $O$ diagnóstico da banalização do desmentido da autoridade simbólica nos núcleos familiares reitera o que é consensual nesta clínica: a lassidão da potência paterna na transmissão primordial efetuada pelo Outro materno. Segundo Brousse (1992, p. 27), "a mãe é um dos nomes da castração". Com essa afirmativa, a autora recupera o fio freudiano, visto que, para Freud, o primeiro encontro com a castração se funda na descoberta mítica de que a mãe não tem o pênis. Ela não tem, como demonstra Lacan (1971/2009), porque ela é o falo. A mulher é um dos nomes de Deus. Na engrenagem que organiza classicamente a metáfora paterna, a mãe é cernida como função no interior da lógica paterna, transmitindo de modo primário o enigma do desejo com uma ausência que presentifica uma incompletude. Este desejo se regula a partir da significação fálica da perda. Nessa interconexão, a ação do Nome-do-Pai possui como quesito a validação do discurso materno à potência paterna. Como vimos mais acima, à figura materna cabe condescender à castração e nomear o pai como representante da exceção, aquele que supostamente detém o falo que ela não tem. Esse é um parâmetro necessário para que o falo possa operar suficientemente como significante do desejo, 
efetuando a passagem do excesso pulsional à organização fantasmática da pulsão.

Com o precário tratamento sexual do real do desejo do Outro, a figura materna eclode como Outro absoluto, agenciador de imperativos de gozo. Logo, a dimensão real do furo, sem o índice fálico, se torna puro motor para o consumo desenfreado. A captura do gozo por meio de uma falicização muito frágil aprisiona o indivíduo ao imaginário e vai levá-lo a ser consumido pelos significantes mestres do discurso do Outro, dos quais não consegue se destacar. 0 fantasma fragilizado em sua lógica essencial de contenção pulsional, predomina na organização libidinal contemporânea.

O Estado moderno e a ordem familiar foram o paradigma político da referência subjetiva ao Outro simbólico na modernidade. A transmissão da castração, a assunção da posição sexuada e a inscrição do objeto perdido foram os modos de interpretação e tratamento para um real que esbarrava na impossibilidade de absolutização da liberdade e da igualdade. Porém, assistimos ao longo da história a uma gama de eventos que abalaram a ação simbólica da ordem familiar na regulação das relações sociais. A nova idade da democracia é marcada pela discursividade pós-moderna, pelos avanços do capitalismo em seu empuxo ao consumo, pelas reivindicações feministas pela liberdade sexual, pela legitimação das separações conjugais, pelo anti-paternalismo e pela desqualificação cerrada de formas verticais de autoridade em favor da horizontalização, bem como pelos discursos identitários. Os alicerces civilizatórios da cultura ocidental cristã não resistiram. Como adverte Coelho dos Santos (2001), a tese freudiana de que a civilização reprime a sexualidade afetou os ideais burgueses, disseminando a crença no potencial patogênico do excesso de interdição a que estiveram submetidos. A própria difusão social da psicanálise também possuiu sua cota de participação no ataque à autoridade paterna e no afrouxamento da censura às pulsões.

As figuras do Outro primordiais não são mais interpretadas pela positividade do que lhes falta enquanto causa de seu desejo. Parece que foram demitidas ou não são mais reconhecidas como doadoras de uma função simbólica. O Outro é devedor de gozo, usurpador de um direito. Em tempos de culto à cobrança da dívida de gozo, em que o direito do cidadão se confunde com o direito a uma satisfação plena e completa, a interrogação recai sobre a capacidade parental em assumir a responsabilidade que lhe cabe de barrar o desejo de morte nas manifestações de gozo de seus filhos. Conforme advoga Melman (2003), os pais mais parecem capturados como funcionários, cuja obrigação é a de garantir o "bem-estar" e a satisfação das expectativas insólitas dos que o cercam. Com o desmantelamento das coordenadas edípicas e o culto ao hedonismo, a sombra de sua majestade o bebê, como apresentação da exceção à castração, 
coloniza as relações de parentesco sem arestas, não comportando nenhum lugar para frustração. Irrompe uma posição feroz e rebelde à castração e, consequentemente, maneiras de gozar arredias à pacificação fantasmática propiciada pelo laço amoroso com o Outro paterno. Em última instância, qualquer exigência de abdicação do gozo parece correr o risco de assumir a toga de abuso de poder e de opressão.

\section{Como tratar o que não se deixa interpretar?}

A clínica contemporânea nos exige uma responsabilidade maior. 0 recurso à interpretação pode desencadear o antigo repúdio à função do Nome-do-Pai. Não é raro que o sujeito contemporâneo manifeste uma atitude opositiva, desdenhosa e se esforce por desmentir a interpretação do analista (Coelho dos Santos, 2016b). O conceito lacaniano de desejo do analista veio responder à questão de como tratar o que não se deixa interpretar. A dívida deste conceito com as psicanalistas inglesas que trouxeram 0 problema da contratransferência é abertamente reconhecida em seu O Seminário, livro 10: A angústia (Lacan, 1962-1963/2005). O desejo do analista "não é sem" a contratransferência, assim como a angústia "não é sem" o objeto. A angústia, recorda Lacan, é um affekt. Ela não é um afeto (stimmung), e sim a matriz de todos os afetos que, diferentemente dela, são enganadores. A angústia é o único índice da presença do real. E o que é o real da angústia na experiência analítica? A angústia (segundo tempo da simbolização do Édipo no fantasma) situa-se, justamente, entre o gozo e o desejo. É um tempo de perda, de encontro com a castração. Freud já advertia que, deste segundo tempo, não existe nenhuma recordação na memória. É tempo mítico, mas, que na experiência analítica, indica a presença de algo - o objeto a - como separado do sujeito. A angústia "não é sem objeto", mas não se pode dizer de que objeto se trata. Este objeto não tem a mesma estrutura que os objetos comuns, objetos da nossa experiência consciente de nosso corpo e do mundo que nos cerca. A única coisa de que se pode ter "a apavorante certeza" é de que uma perda se produziu e que é preciso que o desejo do analista sustente o lugar da falta como causa do desejo. Não há interpretação possível desse hiato. Somente o ato do analista poderá, talvez, introduzir as coordenadas significantes, para que um "sujeito que não é ainda" possa advir como sujeito marcado pela castração.

O lugar do analista não seria mais apenas o de semblante do "sujeito suposto saber" ou do Nome-do-Pai. Sua função não é somente a de encarnar o significante excepcional que opera interpretando o dito, abrindo-o à satisfação do dizer. Na clínica do fantasma, o analista opera como semblante do objeto a. Não é uma interpretação o que se 
espera dele, não é um saber. É preciso fazer ressoar os significantes fora do sentido, convidando o sujeito a fazer um encontro inédito com a dimensão do simbólico em sua conexão direta com o real. Ela não precisa de palavras, não visa decifrar um enigma, mas extrair o objeto com o qual o sujeito goza, arrancando-o do gozo fantasmático, denunciando o fantasma como um arranjo contingente.

Com os sintomas contemporâneos - na medida em que desmentem o lugar alteritário do Outro e abrigam a reivindicação narcísica de "ser tratados como exceção" - precisamos ir além do fantasma. O fantasma é unissex. O sujeito narcísico também. É preciso lhe devolver as dimensões rejeitadas da diferença sexual e da diferença geracional. O lugar do analista é o do parceiro-sintoma. Ele encarna o real traumático da "relação sexual que não há", do mal-entendido entre os sexos. O que se espera como efeito é a identificação ao sinthoma, à conjunção contingente entre $S_{1}$ e objeto a que determina cada ser falante como homem ou mulher. Aprofundando 0 desencontro essencial entre os sexos, trata-se de forçar o gozo autista a articular-se na metáfora ou na suplência do amor. De tal modo que o gozo não seja impossível, mas sim singular, contingente, um artifício fabricado na articulação aos outros gozos.

\section{Referências}

Brodsky, G. (2014). Fundamentos 1 - Comentario del Seminario 11. Buenos Aires: Grama Ediciones.

Brousse, M. H. (1992). La mère dans la psychanalyse. Révue Quarto, $1(47), 25-33$.

Chemana, R. (2013). Un fantasme est analysé. In Lacôte-Destribats et al. (Orgs.), Questions cliniques: qu'appelons-nous fantasme? - Séminaires de l'Association Lacanienne Internationale (pp. 11-24). Paris: ALI.

Coelho dos Santos, T. (2001). Quem precisa de análise hoje? O discurso analítico: novos sintomas e novos laços sociais. Rio de Janeiro: Bertrand Brasil.

Coelho dos Santos, T. (2012). O lugar certo onde colocar o desejo do analista na era dos direitos. Revista aSEPHallus de Orientação Lacaniana, 7(4), 14-26.

Coelho dos Santos, T. (2015). O olhar sem véu: transparência e obscenidade. Revista aSEPHallus de Orientação Lacaniana, 10(20), 4-15. doi:10.17852/1809-709x.2019v12n24p05-16.

Coelho dos Santos, T. (2016a, Setembro). Do saber suposto ao saber exposto ou da identificação ao sintoma ao advento do pesquisador. Congresso Internacional de Psicopatologia Fundamental, Maceió, Alagoas, Brasil, 7. 
Coelho dos Santos, T. (2016b). O Outro que não existe: Verdade verídica, verdades mentirosas e desmentidos veementes. Ágora: Estudos em Teoria Psicanalítica, 19(3), 565-583.

Coelho dos Santos, T. (2017). Sobre o estatuto da lei e do estado de direito na psicanálise. In T. Coelho dos Santos \& F. Malcher (Orgs.), Psicanálise no século XXI: Ideologias políticas, subjetividade, laços sociais e intervenções psicanalíticas (pp. 17-39). Curitiba: CRV.

Coelho dos Santos, T. \& Oliveira, F. L. G. (2017). A atualidade dos termos caráter e personalidade. Revista aSEPHallus de Orientação Lacaniana, 12(24), 5-16. doi:10.17852/1809709x.2019v12n24p05-16.

Fenichel, O. (1973). Teoria Psicoanalitica de lãs Neurosis. Buenos Aires: Paidós. (Obra original publicada em 1957).

Freud, S. (1996a). Três ensaios sobre a teoria da sexualidade. In S. Freud, Edição Standard Brasileira das Obras Psicológicas Completas de Sigmund Freud. (Vol. 7, pp. 117-232). Rio de Janeiro: Imago. (Obra original publicada em 1905).

Freud, S. (1996b). Alguns tipos de caráter encontrados no trabalho psicanalítico. In S. Freud, Edição Standard Brasileira das Obras Psicológicas Completas de Sigmund Freud (Vol. 14, pp. 325350). Rio de Janeiro: Imago. (Obra original publicada em 1916).

Freud, S. (1996c). Conferência XXIII: Os caminhos da formação dos sintomas. In S. Freud, Edição Standard Brasileira das Obras Psicológicas Completas de Sigmund Freud (Vol. 16, pp. 171209). Rio de Janeiro: Imago. (Obra original publicada em 1917).

Freud, S. (1996d). "Uma criança é espancada": uma contribuição ao estudo da origem das perversões sexuais. In S. Freud, Edição Standard Brasileira das Obras Psicológicas Completas de Sigmund Freud (Vol. 17, pp. 191-218). Rio de Janeiro: Imago. (Obra original publicada em 1919).

Freud, S. (1996e). A questão da análise leiga: Conversações com uma pessoa imparcial. In S. Freud, Edição Standard Brasileira das Obras Psicológicas Completas de Sigmund Freud (Vol. 20, pp. 175-250). Rio de Janeiro: Imago. (Obra original publicada em 1926).

Freud, S. (1996f). Novas conferências introdutórias de psicanálise e outros trabalhos: Explicações, aplicações e orientações. In S. Freud, Edição Standard Brasileira das Obras Psicológicas Completas de Sigmund Freud (Vol. 20, pp. 135-154). Rio de Janeiro: Imago. (Obra original publicada em 1933).

Freud, S. (1996g). A divisão do ego no processo de defesa. In S. Freud, Edição Standard Brasileira das Obras Psicológicas 
Completas de Sigmund Freud (Vol. 23, pp. 291-300). Rio de Janeiro: Imago. (Obra original publicada em 1940).

Freud, S. (2010). A dissecção da personalidade psíquica. In S. Freud, Novas conferências introdutórias à psicanálise e outros textos (pp. 140-160). São Paulo: Companhia das Letras. (Obra original publicada em 1933).

Lacan, J. (1974-1975). Le Seminaire, livre 22: R.S.I. (Seminário não publicado).

Lacan, J. (1998a). De uma questão preliminar a todo tratamento possível da psicose. In J. Lacan, Escritos (pp. 537-590). Rio de Janeiro: Jorge Zahar. (Obra original produzida em 1958).

Lacan, J. (1998b). Subversão do sujeito e a dialética do desejo no inconsciente freudiano. In J. Lacan, Escritos (pp. 807-842). Rio de Janeiro: Jorge Zahar. (Obra original produzida em 1960).

Lacan, J. (1998c). O Seminário, livro 11: Os conceitos fundamentais da psicanálise. Rio de Janeiro: Jorge Zahar. (Seminário original proferido em 1964).

Lacan, J. (1999). O Seminário, livro 5: As formações do inconsciente. Rio de Janeiro: Jorge Zahar. (Seminário original proferido em 1957-1958).

Lacan, J. (2004). La logique du fantasme. Paris: Éditions de I'Association Lacanienne Internationale. (Seminário original proferido em 1966-1967).

Lacan, J. (2005). O Seminário, livro 10: A angústia. Rio de Janeiro: Jorge Zahar. (Seminário original proferido em 1962-1963).

Lacan, J. (2009). O Seminário, livro 18: De um discurso que não fosse semblante. Rio de Janeiro: Jorge Zahar. (Seminário original proferido em 1971).

Maleval, J.-C. et al. (2009). Sobre a fantasia no sujeito psicótico: de sua carência e seus substitutos. In V. L. Besset \& H. F. Carneiro (Orgs.), A soberania da clínica na psicopatologia do cotidiano (pp. 13-44). Rio de Janeiro: Garamond.

Melman, C. (2003). O homem sem gravidade: gozar a qualquer preço - Entrevistas por Jean-Pierre Lebrun. Rio de Janeiro: Companhia de Freud.

Miller, J.-A. (2002). Percurso de Lacan: uma introdução. Rio de Janeiro: Jorge Zahar.

Miller, J.-A. (2006). Introdución a la clinicalacaniana - Conferéncias en España. Barcelona: RBA Libros.

Miller, J.-A. (2011). La logica del fantasma. In J.-A. Miller, Donc la lógica de la cura (pp. 373-393). Buenos Aires: Paidós.

Nascimento, M. B. (2010). Alienação, separação e travessia da fantasia. Opção Lacaniana Online, 1(1), 1-15.

Santiago, A. L. (2005). A inibição intelectual na psicanálise. Rio de Janeiro: Jorge Zahar. 


\section{Endereço para correspondência \\ Flavia Lana Garcia de Oliveira}

Universidade Federal do Rio de Janeiro

Instituto de Psicologia - Programa de Pós-Graduação em Teoria Psicanalítica

Av. Pasteur, 250, fundos, Pavilhão Nilton Campos, Urca, CEP 22290-240, Rio de Janeiro - RJ, Brasil

Endereço eletrônico: flavialanago@gmail.com

\section{Tania Coelho dos Santos}

Universidade Federal do Rio de Janeiro

Instituto de Psicologia - Programa de Pós-Graduação em Teoria Psicanalítica

Av. Pasteur, 250, fundos, Pavilhão Nilton Campos, Urca, CEP 22290-240, Rio de Janeiro - RJ, Brasil

Endereço eletrônico: taniacs@openlink.com.br

Recebido em: 16/09/2018

Reformulado em: 17/01/2019

Aceito em: 18/01/2019

\section{Notas}

* Pós-Doutoranda no Programa de Pós-Graduação em Teoria Psicanalítica pela Universidade Federal do Rio de Janeiro (UFRJ) (Rio de Janeiro, Brasil). Bolsista do Programa Nacional de Pós-Doutorado da CAPES (Brasil). Professora Substituta do Instituto de Psicologia da Universidade Federal Fluminense (UFF) (Niterói, Brasil). Membro Adjunto do Instituto Sephora de Ensino e Pesquisa de Orientação Lacaniana (ISEPOL) (Rio de Janeiro, Brasil).

** Pós-doutorado no Departamento de Psicanálise de Paris VIII (Paris, França). Professor Associado, nível IV no Programa de Pós-graduação em Teoria Psicanalítica/UFRJ (Rio de Janeiro, Brasil). Pesquisadora do CNPQ nível 1 C (Brasil). Presidente do Instituto Sephora de Ensino e Pesquisa de Orientação Lacaniana/ ISEPOL (Rio de Janeiro, Brasil) Psicanalista Membro da École de La Cause Freudienne, da Escola Brasileira de Psicanálise e da Associação Mundial de Psicanálise Membro da Associação Universitária de Pesquisa em Psicopatologia Fundamental (Rio de Janeiro, Brasil). Editora de aSEPHallus Revista de Orientação Lacaniana (Rio de Janeiro, Brasil).

Financiamentos: Conselho Nacional de Desenvolvimento Científico e Tecnológico (Bolsa de Produtividade nível IC) e Coordenação de Aperfeiçoamento de Pessoal de Nível Superior (Bolsa de Pós-Doutorado).

Este artigo de revista Estudos e Pesquisas em Psicologia é licenciado sob uma Licença Creative Commons Atribuição-Não Comercial 3.0 Não Adaptada. 